Research Article

\title{
Experimental Study on Oxygen-Enriched Sintering of Vanadium-Titanium Magnetite
}

\author{
Hao Liu, ${ }^{1,2}$ Yuelin Qin (D), ${ }^{3}$ Xinlong Wu, ${ }^{4}$ and Bing Xie ${ }^{5}$ \\ ${ }^{1}$ Ph.D Student in College of Materials Science and Engineering, Chongqing University, Chongqing 400044, China \\ ${ }^{2}$ Lecturer in School of Metallurgy and Materials Engineering, Chongqing University of Science and Technology, \\ Chongqing 401331, China \\ ${ }^{3}$ Associate Professor in School of Metallurgy and Materials Engineering, Chongqing University of Science and Technology, \\ Chongqing 401331, China \\ ${ }^{4}$ Student in School of Metallurgy and Materials Engineering, Chongqing University of Science and Technology, \\ Chongqing 401331, China \\ ${ }^{5}$ College of Materials Science and Engineering, Chongqing University, Chongqing 400044, China
}

Correspondence should be addressed to Yuelin Qin; qinyuelin710@163.com

Received 21 May 2018; Revised 18 August 2018; Accepted 9 September 2018; Published 22 November 2018

Academic Editor: Jean-Marie Nedelec

Copyright ( 2018 Hao Liu et al. This is an open access article distributed under the Creative Commons Attribution License, which permits unrestricted use, distribution, and reproduction in any medium, provided the original work is properly cited.

The influences of various factors, such as oxygen enrichment time, oxygen enrichment load, and ignition temperature, on the technical indices and sintering performance in the vanadium-titanium magnetite sintering process are simulated using sinter pot experiments. The experiments are based on the field production parameters of a sintering trolley in a steel enterprise in southwest China. Prolonged oxygen enrichment time results in the gradual increase in vertical sintering speed, sintering utilization coefficient, sintered ore yield, sintered ore drum strength, and reductivity. However, the low-temperature reduction pulverability of the sintered ore deteriorates. Oxygen enrichment load increases from $0 \mathrm{~m}^{3} / \mathrm{h}$ to $2.9 \mathrm{~m}^{3} / \mathrm{h}$, and yield increases by $1.1 \%$, while the vertical sintering speed and utilization coefficient increase slightly. Sintered ore drum strength increases from $65.33 \%$ to $68.00 \%$, antiwear index decreases to $0.47 \%$, and low-temperature reduction pulverability decreases from $65.07 \%$ to $62.85 \%$. The increased ignition temperature is beneficial to improve the drum strength and yield of the ore but reduces the vertical sintering speed and utilization coefficient. With the increase in ignition temperature, the low-temperature reduction pulverability tends to increase first and then decrease. Changes in oxygen time, oxygen enrichment load, and ignition temperature have no significant effects on the soft melting performance of the sintered ore.

\section{Introduction}

Vanadium-titanium magnetite is rich in vanadium and titanium. These two elements are important strategic resources mainly for steel, nonferrous metals, and chemical raw material production. The vanadium-titanium magnetite resources in China are mostly distributed in Panzhihua, Sichuan, and Chengde, Hebei. The reserves in Panzhihua account for approximately 618 million tons, which is approximately $95 \%$ of the total reserve in China and more than $35 \%$ of global reserves. Compared with the sintering of ordinary iron ore, vanadium-titanium magnetite has lower iron, $\mathrm{FeO}$, and $\mathrm{SiO}_{2}$ contents but higher $\mathrm{TiO}_{2}, \mathrm{MgO}$, and
$\mathrm{Al}_{2} \mathrm{O}_{3}$ contents. These characteristics are not favorable for sintering, resulting in low production, low grade, poor strength, low yield, and high solid energy consumption of the sintered ore $[1,2]$. Numerous studies have shown that few bonding-phase minerals are generated during the sintering of vanadium-titanium magnetite, but abundant perovskites are found in the sinter. These phenomena lead to the deterioration of the sintered ore strength and decrease in yield. Moreover, the low-temperature reduction pulverability rate of the vanadium-titanium sintered ore $\mathrm{RDI}_{-3.15}$ is significantly higher than that of ordinary sintered ore [3-7].

Oxygen-enriched sintering refers to the addition of a certain amount of oxygen in the intake of air during 
sintering to facilitate the sufficient burning of the sintering fuel and sintering process of the reaction. Using the ignition method of oxygen enrichment can improve the oxygen content in the flue gas and reduce the ignition temperature of the fuel. This process results in the full utilization of the solid fuel on the surface, which is beneficial in accelerating the combustion and heat transfer of the surface material solid in the ignition area. Consequently, the sintering productivity is improved, sintering is intensified, and fuel consumption is reduced [8-10]. Under high oxygen content, most of the liquid-phase reaction and mineral formation process may be completed at temperatures below $1400^{\circ} \mathrm{C}$. The concentration of $\mathrm{Fe}^{2+}$ in the liquid phase is low, and the concentration of $\mathrm{CO}$ in the exhaust gas is also reduced. When alkalinity $>1.2-1.5$, a certain amount of calcium ferrite is formed in the solid phase [8]. In addition, the liquid-phase components and crystallization of various minerals are also assimilated in the air according to certain laws. The drawbacks encountered during the sintering of vanadium-titanium magnetite are the lack of strength, low yield, more return mines, and high rate of low-temperature reduction pulverability. These limitations increase the cost of production energy consumption [10]. Oxygen-enriched sintering can effectively improve vertical sintering speed, sintering process, and sintered ore yield.

In this study, the effects of different oxygen enrichment times, oxygen enrichment loads, ignition temperatures, and other factors on the industrial production of the vanadiumtitanium sintered ore are simulated using sinter pot experiments. Changes in performances, such as sintered ore drum strength, antiwear index, reductivity, low-temperature reduction pulverability index, and soft melting performance, are also studied and analyzed. This study provides a basis for using vanadium-titanium magnetite as a raw material in industrial productions and to obtain high-quality sintered ore with high yield.

\section{Experimental Materials and Methods}

2.1. Experimental Materials. All sintered raw materials are obtained from a steel enterprise in southwest China. The main components of iron ore powder, sintered flux, and sintering return mines are listed in Table 1 . The chemical components of coke are shown in Table 2. The full size distribution of the mix ore powder and coke powder is provided, as shown in Figure 1. The sintering proportion scheme during the experiment is shown in Table 3. The basicity of the sintered ore $\left(R=\mathrm{CaO} / \mathrm{SiO}_{2}\right)$ is set to 2.7 because the sintering characteristics of oxygen-enriched sintering are mainly explored in this study.

2.2. Experimental Methods and Devices. The effects of different oxygen enrichment conditions on the sintering performance of vanadium-titanium magnetite are investigated by changing the factors, such as oxygen enrichment time, oxygen enrichment load, and sintering ignition temperature. The influences of these factors on the technical indices and sintered ore quality during sintering are explored. The time
TABLE 1: Chemical composition of raw materials.

\begin{tabular}{lccccccccc}
\hline $\begin{array}{l}\text { Raw } \\
\text { materials }\end{array}$ & $\mathrm{TFe}$ & $\mathrm{SiO}_{2}$ & $\mathrm{CaO}$ & $\mathrm{Al}_{2} \mathrm{O}_{3}$ & $\mathrm{MgO}$ & $\mathrm{TiO}_{2}$ & $\mathrm{~S}$ & $\mathrm{P}$ & LOI \\
\hline $\begin{array}{l}\text { Mix ore } \\
\text { Dolomite }\end{array}$ & - & 5.5 & 4.9 & 2.87 & 2.3 & 5.9 & 0.388 & 0.14 & 2.5 \\
$\begin{array}{l}\text { Lime } \\
\text { Return } \\
\text { ore }\end{array}$ & - & 2.7 & 77.0 & - & - & - & 0.070 & - & 15.0 \\
\hline
\end{tabular}

TABle 2: Proximate analysis and composition analysis of coke.

\begin{tabular}{lccccccc}
\hline \multirow{2}{*}{ Composition } & \multirow{2}{*}{$\mathrm{C}_{\mathrm{Fix}}$} & \multirow{2}{*}{$\mathrm{W}$} & $\mathrm{V}$ & \multicolumn{4}{c}{$\mathrm{A}$} \\
& & & & $\mathrm{CaO}$ & $\mathrm{MgO}$ & $\mathrm{SiO}_{2}$ & $\mathrm{Al}_{2} \mathrm{O}_{3}$ \\
\hline Proportion (\%) & 79.94 & 7.62 & 9.49 & 1.6 & 0.41 & 14.3 & 6.9 \\
\hline
\end{tabular}

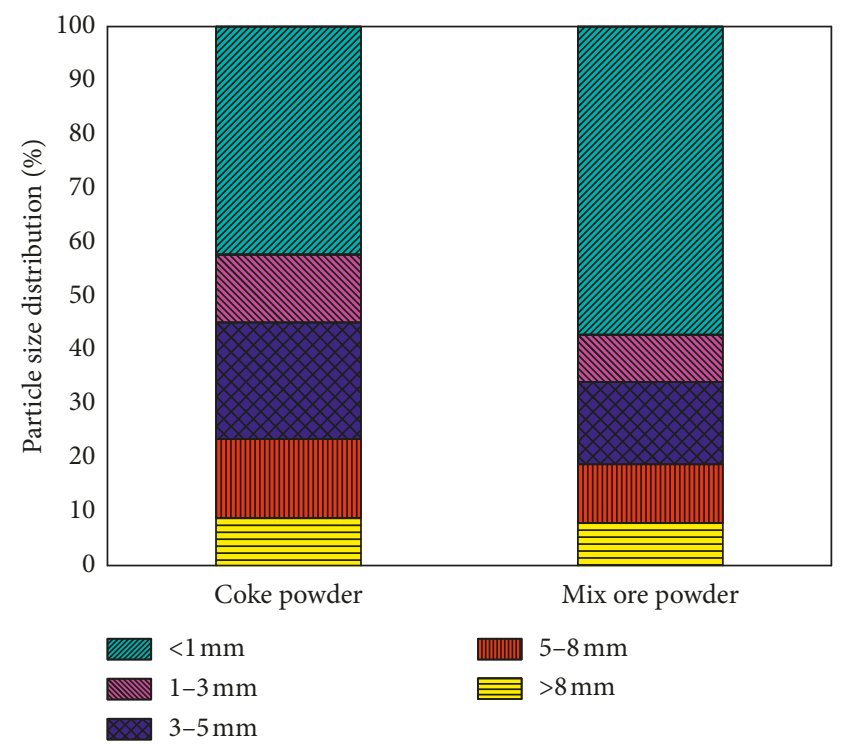

FIgURE 1: The full size distribution of the coke powder and mix ore powder.

TABle 3: Proportion scheme of sintering raw materials (mass fraction, \%).

\begin{tabular}{lccccc}
\hline Raw material & Mix ore & Dolomite & Lime & Return ore & Coke \\
\hline Proportion (\%) & 56.7 & 2.1 & 7.7 & 30 & 3.5 \\
\hline
\end{tabular}

and load to enrich the oxygen in the sinter pot experiment are determined by conversion based on $260 \mathrm{~m}^{2}$ of the effective suction area of a sintering trolley and the actual air volumes of the two main exhaust fans $\left(11000 \mathrm{~m}^{3} / \mathrm{h}\right.$ for each exhaust fan) in a steel enterprise in southwest China.

The influence of sintering oxygen enrichment time is evaluated. The sintering trolley limits the oxygen-enriched flow rate to $2000 \mathrm{~m}^{3} / \mathrm{h}$, and the converted oxygen-enriched flow rate is $1.93 \mathrm{~m}^{3} / \mathrm{h}$ on the sinter pot area. The oxygen enrichment in the bellow is changed. The length of the bellow is $2.3 \mathrm{~m}$. The numbers of bellows are 2, 4, 6, 8, and 10 . The converted times of the sintering process are approximately $3.2,6.4,9.6,12.8$, and $16.0 \mathrm{~min}$. 
The oxygen enrichment load is based on the three kinds of loads of the sintering trolley, namely, 1000 (low load), 2000 (medium load), and $3000 \mathrm{~m}^{3} / \mathrm{h}$ (high load). The converted equivalent sinter pot area oxygen enrichment loads are $0.97,1.93$, and $2.90 \mathrm{~m}^{3} / \mathrm{h}$, respectively. According to the fixed six-bellow oxygen enrichment system, the converted time of the sintering process in the sinter pot is approximately $9.6 \mathrm{~min}$.

In the experiment for sintering oxygen-enriched ignition, increased oxygen enrichment will increase the theoretical sintering ignition temperature. In addition, the ignition fuel used in the laboratory sinter pot experiment is liquefied petroleum gas with a quite different calorific value and composition from those of blast furnace gas used by the sintering trolley. Therefore, the influence of ignition temperature on the sintering process is also studied experimentally.

The specific experimental scheme of oxygen-enriched sintering of vanadium-titanium magnetite is shown in Table 4.

After the raw materials are prepared in accordance with the proportion scheme in Table 3, the materials are first artificially mixed evenly on an iron plate. Then, the materials are put into a cylinder mixer (diameter $\times$ length of $600 \mathrm{~mm} \times$ $800 \mathrm{~mm}$ ) and mixed for a mixed granulation time of $5 \mathrm{~min}$. An appropriate amount of water is sprayed during mixing to wet the mixture, and the final moisture content of the mixture is controlled at $8.0 \% \pm 0.5 \%$. Then, the mixed raw materials are added into the sinter pot of $\varnothing 300 \mathrm{~mm} \times$ $900 \mathrm{~mm}$. The thickness of the control material layer is approximately $600 \mathrm{~mm}$. Approximately $3 \mathrm{~kg}$ of the sintered ore is paved at the bottom of the sinter pot as the bottom material before that. The particle size of the sintered ore is $10 \sim 16 \mathrm{~mm}$. The excess oxygen during sintering is provided by an additional oxygen distribution device (Figure 2). This device is equipped with a stainless steel cone-shaped oxygen supply cover and a bottom hole for oxygen. The holes are evenly distributed at an angle of $60^{\circ}$, and the oxygen supply channel is naturally formed. After charging, the exhaust fan is controlled, in which the ignition negative pressure is $8.0 \mathrm{kPa}$, ignition time is $2 \mathrm{~min}$, and the sinter negative pressure is $14 \mathrm{kPa}$. After sintering is completed, the technical indices, mechanical performance, and metallurgical performance of the sintered ore are determined. The phase composition of the sintered ore is analyzed by a Zeiss Axioskop 40 polarizing microscope and LEICA Q500 image analyzer.

The sintered ore drum strength is detected using GB 8209-87. The proportion of the amount in excess of $6.3 \mathrm{~mm}$ of the drum sample total mass is considered as the drum strength, and the proportion of the amount that is less than $0.5 \mathrm{~mm}$ of the drum sample total mass is the antiwear index. Reductivity is tested by experiments according to GB/T 13241-91. A weight loss method is used to determine the iron ore reductivity. The average of the double specimen is considered, and the absolute value of the range is not more than 5\%. The low-temperature reduction pulverability $\left(\mathrm{RDI}_{>3.15}\right)$ is determined according to the GB/T13242-91 method. After the experiment is completed, the ratio of the mass of the particles with the size greater than $3.15 \mathrm{~mm}$ grade and the total mass of the drum sample after reduction is considered as the evaluation standard.

No uniform test for determining the softening property is available. This property can be determined using the following parameters: sample size, $10-12.5 \mathrm{~mm}$; stock column height, $40 \mathrm{~mm}$; upper coke, $15 \mathrm{~g}$; lower coke, $20 \mathrm{~g}$; load, $1.0 \mathrm{~kg} / \mathrm{cm}^{2}$; and gas flow rate, $15 \mathrm{~L} / \mathrm{min}$. The reduction gas composition is $\mathrm{CO} / \mathrm{N}_{2}=30 / 70$. The heating rate when it is below $900^{\circ} \mathrm{C}$ is $10^{\circ} \mathrm{C} / \mathrm{min}$. However, when it is at $900^{\circ} \mathrm{C}$, it is placed under constant temperature for $60 \mathrm{~min}$. When it is above $900^{\circ} \mathrm{C}$, the rate is $5^{\circ} \mathrm{C} / \mathrm{min}$. When it is below $400^{\circ} \mathrm{C}, \mathrm{N}_{2}$ is injected to protect the test sample. When it is at $400^{\circ} \mathrm{C}$, reduction gas is provided. The temperature at which the rate of shrinkage of the stock column is $10 \%$ is considered as the start softening temperature $\left(T_{\mathrm{a}}\right)$, while that at which the rate of shrinkage is $40 \%$ is the softening end temperature $\left(T_{\mathrm{s}}\right)$. The softening temperature range is $\Delta T_{\mathrm{sa}}=T_{\mathrm{s}}-T_{\mathrm{a}}$, and $T_{\mathrm{m}}$ is the temperature at which the slag iron starts to drip.

\section{Results and Discussion}

3.1. Effects of Different Oxygen Enrichment Times on the Sintering Performance of Vanadium-Titanium Magnetite. Table 5 shows the main technical indices of the sintering of vanadium-titanium magnetite at different oxygen enrichment times. Compared with the absence of oxygen enrichment, the sintered ore drum strength, antiwear properties, and yield improved after oxygen-enriched sintering. This phenomenon is due to the fact that oxygenenriched sintering increases the oxidizing atmosphere during sintering. Consequently, fuel combustion is more sufficient, resulting in the formation of the sintering liquid phase. Thus, favorable conditions for the production of more high-quality calcium ferrite bonding phases are provided, resulting in the improvement of aforementioned indices. In addition, oxygen-enriched sintering ensures full combustion of fuel to reduce the local reduction, combustion layer temperature, and thickness. This process also reduces the increase in the amount of liquid phases, which is conducive to agglomeration and mineralization of sintered ore powder, and can also improve the strength and yield of the sintered ore.

In addition, the vertical sintering rate and sintering utilization coefficient are improved after oxygen-enriched sintering, which are all higher than $22.57 \mathrm{~mm} / \mathrm{min}$ and $1.58 \mathrm{t} /\left(\mathrm{m}^{2} \cdot \mathrm{h}\right)$. These characteristics are caused by the more sufficient fuel combustion during oxygen-enriched sintering, resulting in increased combustion layer temperature. This process accelerates the solid-phase reaction of the sintered material layer and the vertical sintering speed, such that the sintering utilization coefficient is improved.

The main components and $\mathrm{FeO}$ content of the sintered ore after different sintering oxygen enrichment times are shown in Table 6 and Figure 3. The main components of the sintered ore are slightly changed after oxygen enrichment time, but the $\mathrm{FeO}$ content in the finished sintered ore is reduced from $6.50 \%$ to $5.95 \%$. These characteristics are caused by the more adequate fuel combustion during 
TABLE 4: Experimental scheme.

\begin{tabular}{lccc}
\hline Sample & Oxygen-enriched time length $(\mathrm{min})$ & Oxygen-enriched volume $\left(\mathrm{m}^{3} \cdot \mathrm{h}^{-1}\right)$ & Temperature of ignition $\left({ }^{\circ} \mathrm{C}\right)$ \\
\hline S0 & 0 & 0 & 1100 \\
S1-1 & 3.2 & 1.93 & 1100 \\
S1-2 & 6.4 & 1.93 & 1100 \\
S1-3 & 9.6 & 1.93 & 1100 \\
S1-4 & 12.8 & 1.93 & 1100 \\
S1-5 & 16 & 1.93 & 1100 \\
S2-1 & 9.6 & 0.97 & 1100 \\
S2-2 & 9.6 & 1.93 & 1100 \\
S2-3 & 9.6 & 2.90 & 1100 \\
S3-1 & 0 & 0 & 1000 \\
S3-2 & 0 & 0 & 1050 \\
S3-3 & 0 & 0 & 1100 \\
S3-4 & 0 & 0 & 1150 \\
S3-5 & 0 & 0 & 1200 \\
S3-6 & 0 & 0 & 1250 \\
\hline
\end{tabular}

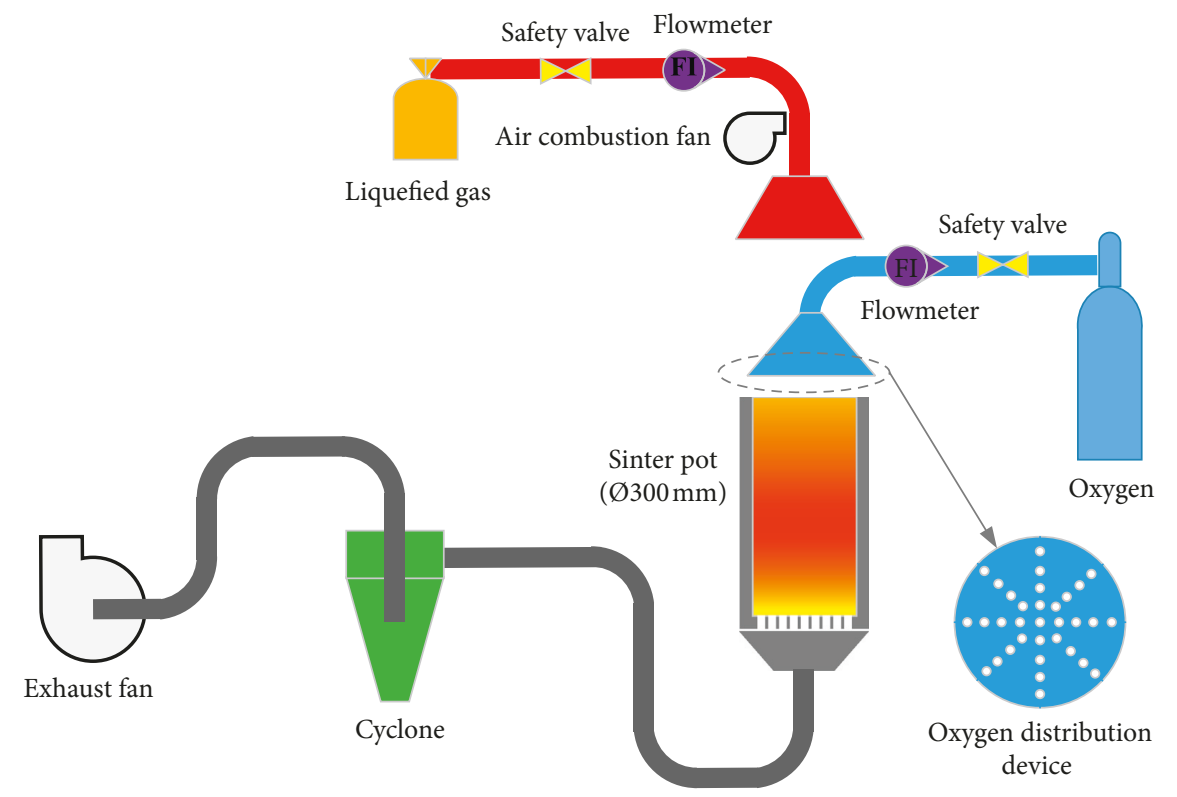

Figure 2: Schematic diagram of the sintering pot device and oxygen enrichment device.

TABLE 5: Technical indices of the sintering process for different oxygen enrichment times.

\begin{tabular}{lcccccc}
\hline Sample & Time $(\mathrm{min})$ & DI $(\%)$ & $\%$ & Field $(\%)$ & SS $(\mathrm{mm} / \mathrm{min})$ & $\begin{array}{c}\text { Utilization factor of effective area } \\
(\mathrm{UFEA}) \mathrm{t} /\left(\mathrm{m}^{2} \cdot \mathrm{h}\right)\end{array}$ \\
\hline S0 & 0 & 65.33 & 5.27 & 82.29 & 22.57 & 1.58 \\
S1-1 & 3.2 & 66.65 & 4.13 & 83.74 & 22.9 & 1.61 \\
S1-2 & 6.4 & 65.53 & 5.03 & 82.72 & 23.17 & 1.64 \\
S1-3 & 9.6 & 65.39 & 4.78 & 83.09 & 22.98 & 1.59 \\
S1-4 & 12.8 & 65.33 & 4.8 & 83.66 & 24.64 & 1.72 \\
S1-5 & 16 & 66.67 & 5.02 & 82.57 & 22.8 & 537 \\
\end{tabular}

SS: sintering speed; WT: waste gas temperature.

oxygen-enriched sintering, which decreases the CO produced by incomplete combustion of coke. Thus, oxygenenriched sintering reduces the local reduction reaction, resulting in lowered $\mathrm{FeO}$ content. In addition, iron ore powder used during sintering is mainly magnetite $\left(\mathrm{Fe}_{3} \mathrm{O}_{4}\right)$. After oxygen-enriched sintering, the oxidizing atmosphere increases during sintering, and some $\mathrm{Fe}_{3} \mathrm{O}_{4}$ is oxidized into $\mathrm{Fe}_{2} \mathrm{O}_{3}$, further reducing the $\mathrm{FeO}$ in the sintered ore.

Figure 4 shows the test results of the sintered ore reductivity and reduction pulverability for different sintering oxygen enrichment times. The reductivity of the sintered ore increases from $78.10 \%$ to $80.08 \%$, while the reduction 
TABLE 6: Analysis of the composition of the finished sintered ore for different oxygen enrichment times.

\begin{tabular}{lccccccccc}
\hline Sample & Time (min) & $\mathrm{TFe}$ & $\mathrm{FeO}$ & $\mathrm{SiO}_{2}$ & $\mathrm{CaO}$ & $\mathrm{MgO}$ & $\mathrm{Al}_{2} \mathrm{O}_{3}$ & $\mathrm{TiO}_{2}$ & $\mathrm{R}$ \\
\hline S0 & 0 & 46.99 & 6.50 & 6.08 & 15.66 & 3.50 & 3.06 & 4.59 & 2.58 \\
S1-1 & 3.2 & 46.80 & 6.36 & 6.04 & 15.81 & 3.49 & 3.00 & 4.54 & 2.62 \\
S1-2 & 6.4 & 46.76 & 6.25 & 6.12 & 14.00 & 3.54 & 3.09 & 4.38 \\
S1-3 & 9.6 & 46.87 & 6.14 & 5.98 & 15.22 & 3.53 & 3.04 & 4.53 & 2.29 \\
S1-4 & 12.8 & 46.93 & 6.14 & 6.12 & 15.25 & 3.50 & 3.03 & 4.33 & 2.49 \\
S1-5 & 16 & 46.83 & 5.95 & 6.14 & 15.66 & 3.51 & 3.06 & 4.62 & 2.55 \\
\hline
\end{tabular}

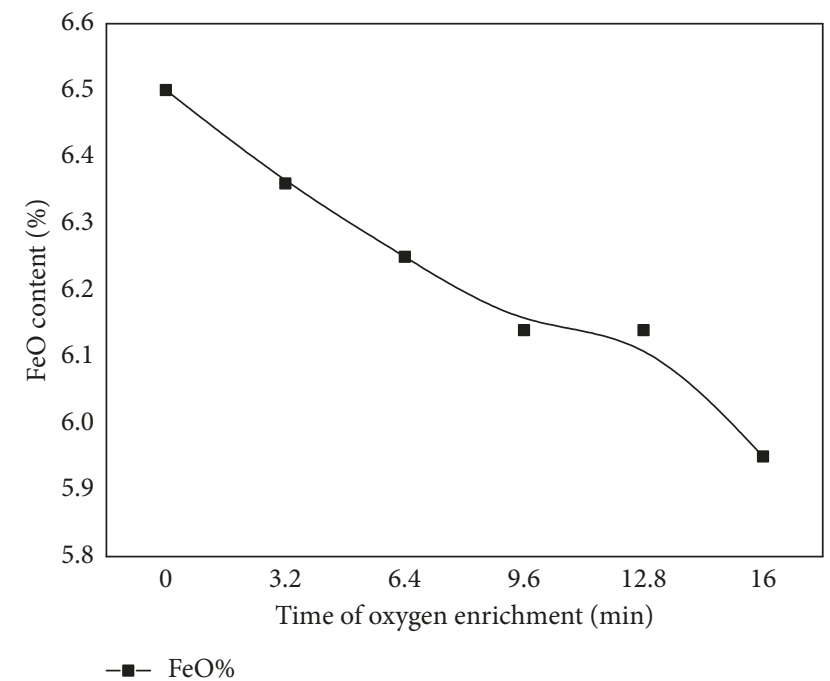

Figure 3: FeO content in the sintered ore for different oxygen enrichment times.

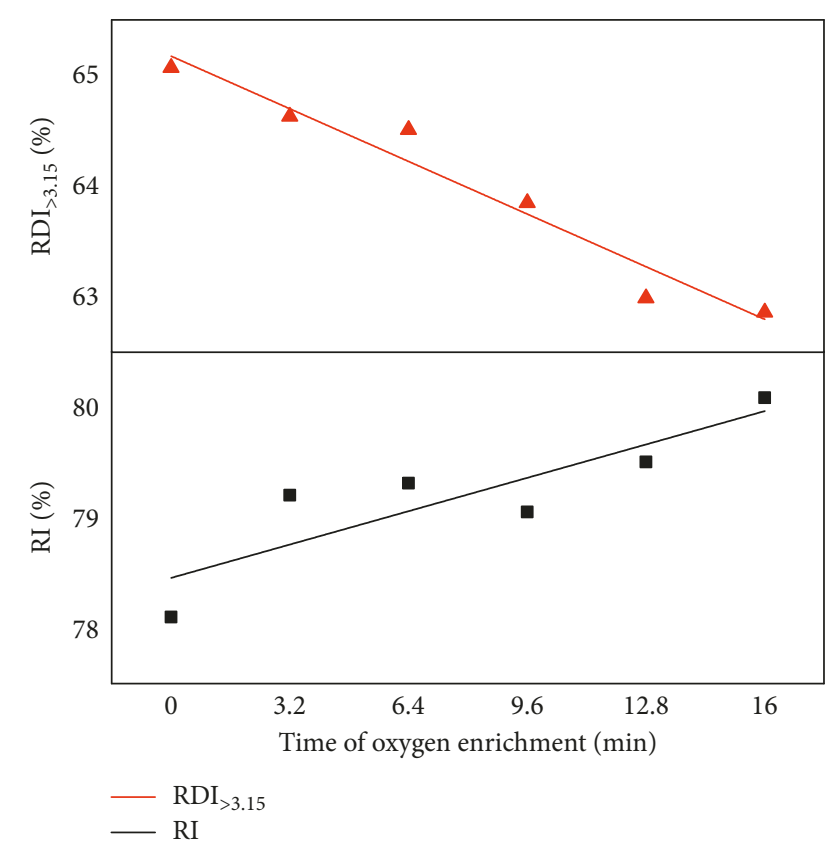

FIGURE 4: Reductivity and reduction pulverability of the sintered ore for different sintering oxygen enriched times.

pulverability decreases from $65.07 \%$ to $62.86 \%$ with the increase in sintering oxygen enrichment time. These results are due to the decreased $\mathrm{FeO}$ content in the sintered ore caused by the prolonged sintering oxygen enrichment time. This process will reduce the phase production of perovskite, kirschsteinite, and other minerals with poor reductivity but increase hematite, calcium ferrite, and other minerals with good reductivity, thereby improving the reduction of the sintered ore [11-13]. However, the hematite in the sintered ore undergoes crystal transformation during reduction $\left(\mathrm{Fe}_{2} \mathrm{O}_{3}-\mathrm{Fe}_{3} \mathrm{O}_{4}-\mathrm{FeO}\right)$, leading to great internal stress. This process causes the pulverization of the sintered ore by mechanical force, resulting in poor reduction pulverability of the sintered ore $[14,15]$. During sintering, the time of oxygen enrichment is increased, and the hematite produced by reoxidation in the sintered ore increases. Thus, a great amount of hematite undergoes lattice transformation and pulverability during reduction, which reduces the $\mathrm{RDI}_{>3.15}$.

Table 7 shows the test results of the softening performance of the sintered ore for different oxygen enrichment times. No remarkable changes are observed in $T_{\mathrm{a}}$ and $T_{\mathrm{s}}$ of the sintered ore with prolonged oxygen enrichment time. However, the softening interval decreases from $51^{\circ} \mathrm{C}$ to $39^{\circ} \mathrm{C}$, and $T_{\mathrm{m}}$ decreases by $33^{\circ} \mathrm{C}$.

3.2. Effects of Different Oxygen Enrichment Loads on the Sintering Performance of Vanadium-Titanium Magnetite. The main technical indices of the vanadium-titanium magnetite sintering process for different oxygen enrichment loads are shown in Table 8 . With the increase in oxygen enrichment load, the drum strength of the sintered ore increases from $65.33 \%$ to $68.00 \%$, antiwear index decreases from $5.27 \%$ to $4.80 \%$, and yield increases from $82.29 \%$ to $83.39 \%$. These phenomena are due to the enhanced oxidizing atmosphere during sintering caused by the increased oxygen enrichment load. This process results in more sufficient combustion of coke in the sintering mixture, increased temperature of the combustion layer, and increased thickness. Consequently, the sintering liquid phase is formed and increased, and this phase is conducive to the agglomeration and mineralization of the sintered ore, thereby improving the strength and yield of the sintered ore. The vertical sintering rate and utilization coefficient increase first and then decrease with increased oxygen enrichment load. This phenomenon is due to the more complete combustion process caused by oxygen-enriched sintering. Thus, the solid-phase reaction of the sintered material layer and the vertical sintering speed are accelerated, thereby increasing the sintering utilization coefficient. However, the sintering temperature remarkably increases because of the very high oxygen content. This process results in the early formation of 
TABLE 7: Softening performance of the sintered ore for different oxygen enrichment times.

\begin{tabular}{|c|c|c|c|c|c|}
\hline Sample & Time $(\min )$ & $T_{\mathrm{a}}\left({ }^{\circ} \mathrm{C}\right)$ & $T_{\mathrm{s}}\left({ }^{\circ} \mathrm{C}\right)$ & $\Delta T_{\mathrm{sa}}\left({ }^{\circ} \mathrm{C}\right)$ & $T_{\mathrm{m}}\left({ }^{\circ} \mathrm{C}\right)$ \\
\hline S0 & 0 & 1145 & 1196 & 51 & 1388 \\
\hline S1-1 & 3.2 & 1155 & 1199 & 44 & 1359 \\
\hline S1-2 & 6.4 & 1158 & 1198 & 40 & 1356 \\
\hline S1-3 & 9.6 & 1155 & 1197 & 42 & 1360 \\
\hline S1-4 & 12.8 & 1150 & 1199 & 49 & 1356 \\
\hline S1-5 & 16 & 1153 & 1192 & 39 & 1355 \\
\hline
\end{tabular}

TABle 8: Technical indices of the sintering process with different oxygen enrichment loads.

\begin{tabular}{|c|c|c|c|c|c|c|c|}
\hline Sample & Oxygen enriched $\left(\mathrm{m}^{3} / \mathrm{h}\right)$ & DI (\%) & AI (\%) & Yield (\%) & $\mathrm{SS}(\mathrm{mm} / \mathrm{min})$ & $\mathrm{UC}\left(\mathrm{m}^{2} \cdot \mathrm{h}\right)$ & WT $\left({ }^{\circ} \mathrm{C}\right)$ \\
\hline S0 & 0 & 65.33 & 5.27 & 82.29 & 22.57 & 1.58 & 463 \\
\hline S2-1 & 0.97 & 65.36 & 5.07 & 83.09 & 24.70 & 1.73 & 516 \\
\hline S2-2 & 1.93 & 66.00 & 5.03 & 82.34 & 22.49 & 1.59 & 487 \\
\hline S2-3 & 2.9 & 68.00 & 4.80 & 83.39 & 21.90 & 1.54 & 466 \\
\hline
\end{tabular}

IT: ignition temperature; DI: drum index; AI: antiwear index; SS: sintering speed; UC: utilization coefficient; WT: waste gas temperature.

the sintering liquid phase, leading to the increase in the volume of the liquid phase. Consequently, the sintered mixture gap becomes jammed, and this condition reduces the vertical sintering speed and sintering utilization coefficient.

Table 9 shows the main components of the sintered ore with different oxygen enrichment loads. The main component of the sintered ore does not remarkably change with the increase in sintering oxygen enrichment load. However, the $\mathrm{FeO}$ content in the sintered ore decreases from $6.50 \%$ to $6.14 \%$. The increase in oxygen enrichment load results in the sufficient combustion of coke in the sintered mixture to reduce the local reduction reaction and the amount of $\mathrm{FeO}$ produced. Increasing the oxygen enrichment load enhances the oxidizing atmosphere during sintering, and this process can oxidize part of the magnetite into hematite and reduce the $\mathrm{FeO}$ content in the sintered ore.

Figure 5 shows the phase diagram of the finished sintered ore with different oxygen enrichment loads. The main components of the sintered ore are hematite, magnetite, calcium ferrite, calcium silicate, and a small amount of perovskite. Increasing the oxygen-enriched content of the sintered ore results in increased hematite content but decreased magnetite content in the sintered ore, but magnetite content decreases. After oxygen enrichment of the sintered ore, the sintering atmosphere shows a certain degree of oxidability. At the same time, the magnetite content in the sintered ore after the oxygen enrichment is decreased.

Figure 5 shows the test results of $\mathrm{RDI}_{>3.15}$ of the sintered ore with different oxygen enrichment loads. $\mathrm{RDI}_{>3.15}$ decreases from $65.07 \%$ to $62.85 \%$ with the increase in sintering oxygen enrichment load (Figure 3 ). The greater the oxygen enrichment load is, the more obvious the decrease in $\mathrm{RDI}_{>3.15}$ is. Figure 6 shows that the sintering oxygen enrichment load increases, and the hematite content in the sintered ore increases. During reduction, a large amount of hematite changes into the crystal form, resulting in internal stress, and this process deteriorates the sintered ore $\mathrm{RDI}_{>3.15}$.

Table 10 shows the test results of the softening performance of the sintered ore with different oxygen enrichment loads. $T_{\mathrm{a}}$ and $T_{\mathrm{s}}$ of the sintered ore show no obvious changes as the oxygen enrichment load increases. The softening interval is reduced by $9^{\circ} \mathrm{C}$, and $T_{\mathrm{m}}$ has declined.

3.3. Effects of Different Ignition Temperatures on the Sintering Performance of Vanadium-Titanium Magnetite. Table 11 shows the technical indices in the sinter pot experiment with different ignition temperatures. The sintering drum strength and yield increase with the sintering ignition temperature, but the vertical sintering speed and sintering utilization coefficient gradually decrease. These results may have been caused by the insufficient supply of heat at low ignition temperature. Consequently, the sintered mixture cannot form a good melt such that the sintered raw material cannot be well formed into blocks and results in low strength. At high ignition temperature, the sintering material layer temperature is high and can form more liquid phases to better bond the ore powder. Thus, the strength of the sintered ore is increased. However, the increase in the amount of liquid phase is not conducive to the gas permeability of the sintered material layer, and the sintering rate is lowered, resulting in a decrease in the sintering utilization coefficient.

Figure 7 shows the test results of the reductivity and $\mathrm{RDI}_{>3.15}$ of the finished sintered ore at different ignition temperatures. No evident changes are found in the reduction of the sintered ore with the increase in ignition temperature, but $\mathrm{RDI}_{>3.15}$ increases first and then decreases. When the ignition temperature is $1150^{\circ} \mathrm{C}$, the sintering $\mathrm{RDI}_{>3.15}$ reaches the maximum value of $66.29 \%$. This phenomenon may have been caused by the insufficient heat at low ignition temperature, resulting in the nonformation of a good melt from the sintered mixture. The sintered ore has remarkable assimilation degree and low strength. An appropriate increase in ignition temperature is conducive to the formation of the sintered liquid phase, increasing the sintered ore strength. Too high sintering temperature overburns the sintered ore, resulting in a high amount of the vitreous material. Cracking easily occurs during low-temperature 
TABLE 9: Composition of the finished sintered ore with different oxygen enrichment loads.

\begin{tabular}{|c|c|c|c|c|c|c|c|c|c|}
\hline Sample & Oxygen enrichment load $\left(\mathrm{m}^{3} / \mathrm{h}\right)$ & $\mathrm{TFe}$ & $\mathrm{FeO}$ & $\mathrm{SiO}_{2}$ & $\mathrm{CaO}$ & $\mathrm{MgO}$ & $\mathrm{Al}_{2} \mathrm{O}_{3}$ & $\mathrm{TiO}_{2}$ & $\mathrm{R}_{2}$ \\
\hline S0 & 0 & 46.99 & 6.50 & 6.08 & 15.66 & 3.50 & 3.06 & 4.59 & 2.58 \\
\hline S2-1 & 0.97 & 46.88 & 6.42 & 6.14 & 15.20 & 3.51 & 3.09 & 4.55 & 2.48 \\
\hline S2-2 & 1.93 & 46.87 & 6.24 & 6.08 & 15.03 & 3.54 & 3.03 & 4.55 & 2.47 \\
\hline S2-3 & 2.9 & 46.87 & 6.14 & 5.98 & 15.22 & 3.53 & 3.04 & 4.53 & 2.55 \\
\hline
\end{tabular}

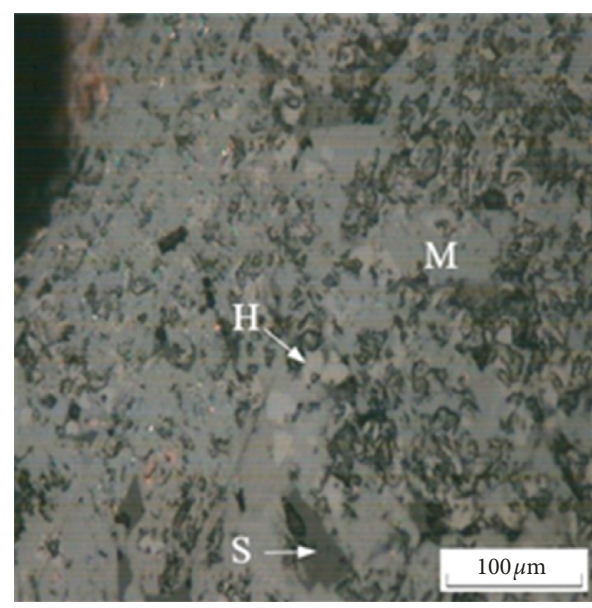

(a)

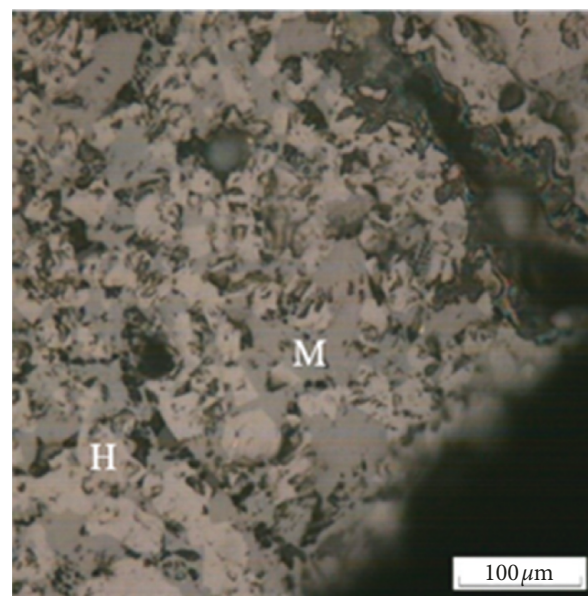

(c)

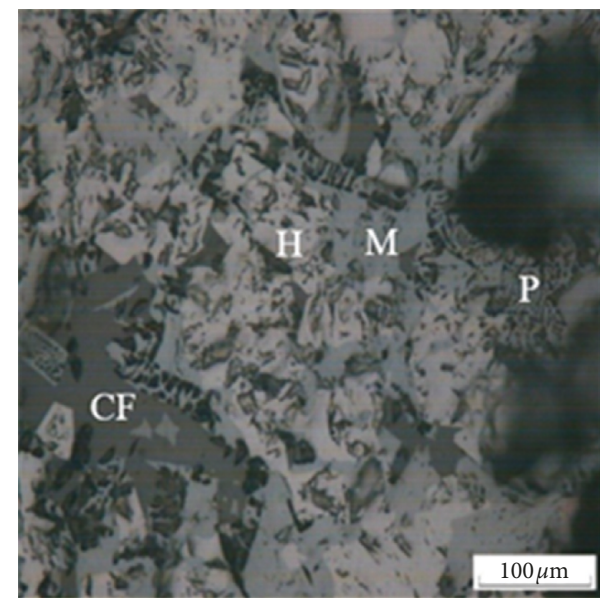

(b)

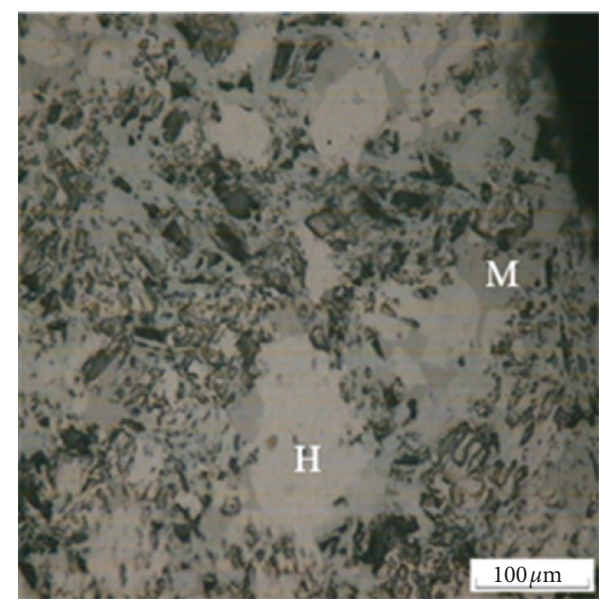

(d)

Figure 5: Phase diagrams of finished sintered ores with different oxygen enrichment loads: (a) 0; (b) 0.97; (c) 1.93; (d) 2.9. H: hematite; M: magnetite; P: perovskite; CF: calcium ferrite; S: calcium silicate.

reduction, leading to the deterioration of sintered ore $\mathrm{RDI}_{>3.15}$.

Table 12 shows the soft melting performance of the sintered ore at different ignition temperatures. The sintered ore $T_{\mathrm{a}}$, softening interval, and $T_{\mathrm{m}}$ do not change significantly. Only $T_{\mathrm{s}}$ slightly increases, indicating that the increase in ignition temperature has little effect on sintered ore soft melting performance.

\section{Conclusion}

(1) The technical indices, such as yield, vertical sintering speed, utilization coefficient, and drum strength, gradually increase with the increase in oxygen enrichment time during sintering. However, the $\mathrm{FeO}$ content in the sintered ore is gradually reduced. The increase in oxygen enrichment time is beneficial in improving the reducibility of the sintered ore, but this process will deteriorate the $\mathrm{RDI}_{>3.15}$ of the sintered ore. Prolonging the oxygen enrichment time has no significant effect on the soft melting performance of the sintered ore.

(2) Increasing the oxygen enrichment load during sintering results in increased drum strength from $68.33 \%$ to $68.00 \%$, decreased antiwear index from $5.27 \%$ to $4.80 \%$, and increased yield from $82.29 \%$ to 


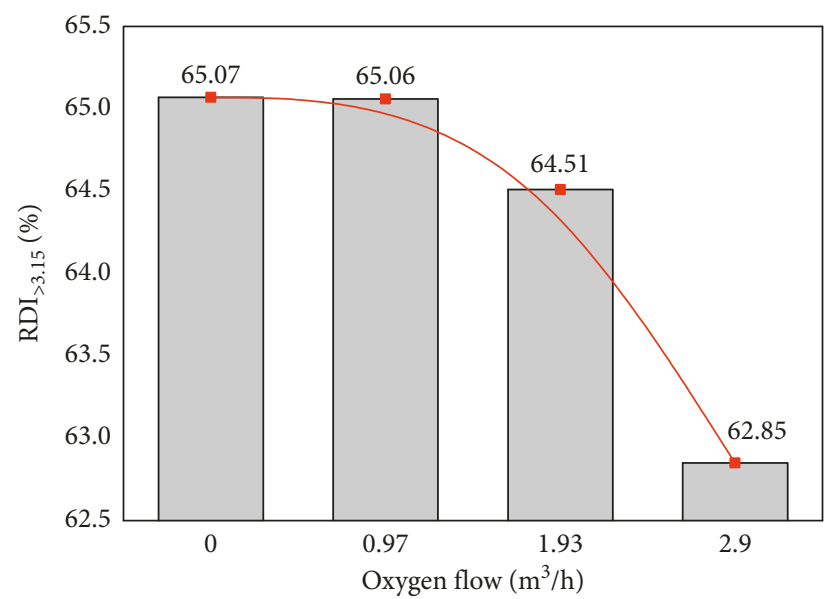

FIGURE 6: Low-temperature reduction pulverability $\left(\mathrm{RDI}_{>3.15}\right)$ of the sintered ore with different oxygen enrichment loads.

TABLE 10: Softening performance of the sintered ore with different oxygen enrichment loads.

\begin{tabular}{|c|c|c|c|c|c|}
\hline Sample & Oxygen enrichment load $\left(\mathrm{m}^{3} / \mathrm{h}\right)$ & $T_{\mathrm{a}}\left({ }^{\circ} \mathrm{C}\right)$ & $T_{\mathrm{s}}\left({ }^{\circ} \mathrm{C}\right)$ & $\Delta T_{\mathrm{sa}}\left({ }^{\circ} \mathrm{C}\right)$ & $T_{\mathrm{m}}\left({ }^{\circ} \mathrm{C}\right)$ \\
\hline S0 & 0 & 1145 & 1196 & 51 & 1388 \\
\hline S2-1 & 0.97 & 1150 & 1193 & 43 & 1357 \\
\hline S2-2 & 1.93 & 1152 & 1195 & 43 & 1358 \\
\hline S2-3 & 2.9 & 1155 & 1197 & 42 & 1360 \\
\hline
\end{tabular}

TABLE 11: Technical indices of the sintering process at different ignition temperatures.

\begin{tabular}{lcccccc}
\hline Sample & IT $\left({ }^{\circ} \mathrm{C}\right)$ & DI $(\%)$ & AI $(\%)$ & Yield $(\%)$ & SS $(\mathrm{mm} / \mathrm{min})$ & $\begin{array}{c}\text { Utilization factor of effective area } \\
(\mathrm{UFEA}) \mathrm{t} /\left(\mathrm{m}^{2} \cdot \mathrm{h}\right)\end{array}$ \\
\hline S3-1 & 1000 & 62.67 & 4.00 & 82.31 & 25.67 & 1.78 \\
S3-2 & 1050 & 62.87 & 3.41 & 81.70 & 25.21 & 1.75 \\
S3-3 & 1100 & 65.33 & 5.27 & 82.29 & 22.57 & 1.58 \\
S3-4 & 1150 & 69.33 & 3.53 & 82.20 & 19.51 & 1.37 \\
S3-5 & 1200 & 65.33 & 3.17 & 83.69 & 22.14 & 1.55 \\
S3-6 & 1250 & 69.33 & 4.13 & 85.00 & 19.80 & 453 \\
\hline
\end{tabular}

IT: ignition temperature; DI: drum index; AI: antiwear index; SS: sintering speed; UC: utilization coefficient; WT: waste gas temperature.

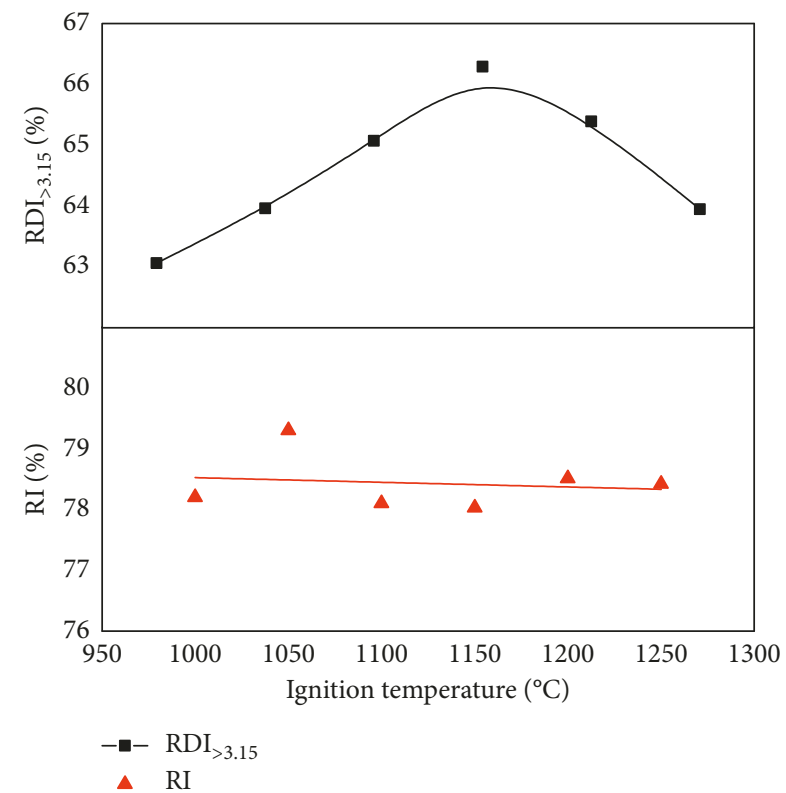

FIGURE 7: Sintered ore reductivity and $\mathrm{RDI}_{>3.15}$ at different ignition temperatures.
TABLE 12: Sintered ore softening performance in the sintering pot experiment at different ignition temperatures.

\begin{tabular}{lccccc}
\hline Sample & $\begin{array}{c}\text { Ignition } \\
\text { temperature }\left({ }^{\circ} \mathrm{C}\right)\end{array}$ & $T_{\mathrm{a}}\left({ }^{\circ} \mathrm{C}\right)$ & $T_{\mathrm{s}}\left({ }^{\circ} \mathrm{C}\right)$ & $\Delta T_{\mathrm{sa}}\left({ }^{\circ} \mathrm{C}\right)$ & $T_{\mathrm{m}}\left({ }^{\circ} \mathrm{C}\right)$ \\
\hline S3-1 & 1000 & 1148 & 1189 & 41 & 1385 \\
S3-2 & 1050 & 1146 & 1192 & 46 & 1380 \\
S3-3 & 1100 & 1145 & 1196 & 51 & 1388 \\
S3-4 & 1150 & 1150 & 1193 & 43 & 1378 \\
S3-5 & 1200 & 1153 & 1197 & 44 & 1379 \\
S3-6 & 1250 & 1151 & 1199 & 48 & 1381 \\
\hline
\end{tabular}

83.39\%. However, the vertical sintering speed and utilization coefficient are reduced.

(3) Increasing the oxygen enrichment load during sintering will increase the hematite content but reduce the magnetite content in the sintered ore. This process results in the gradual decrease of the $\mathrm{RDI}_{>3.15}$ of the sintered ore. However, no significant effect on soft melting performance of the sintered ore is found.

(4) Increasing the ignition temperature is beneficial in improving the strength and yield of the sintered ore. 
However, too high ignition temperature will reduce the vertical sintering speed and utilization coefficient. The $\mathrm{RDI}_{>3.15}$ of the sintered ore first increases and then decreases when the ignition temperature is increased. No evident changes are observed in the reductivity and soft melting performance.

\section{Data Availability}

The data used to support the findings of this study are included within the article.

\section{Conflicts of Interest}

The authors declare that they have no conflicts of interest.

\section{Acknowledgments}

The authors would like to acknowledge the National Natural Science Foundation of China (No. 51604054) and Research Foundation of Chongqing University of Science \& Technology (Nos. CK2015B08 and CK2016Z04).

\section{References}

[1] M. G. He, D. J. Jiang, X. Y. Xiao, K. Yi, W. D. Zhang, and G. Guo, "Practice of two times ignition process of vanadiumtitanium magnetite sintering," Sintering and Pelletizing, vol. 40, no. 6, pp. 15-17, 2015.

[2] X. H. Fan, L. B. Xie, M. Gan, X. L. Chen, and L. H. Yuan, "Roasting characteristics of magnesium pellets and mechanism of strengthening concretion," Journal of Central South University, vol. 44, no. 2, pp. 449-455, 2013.

[3] Y. Q. Sun, S. T. Yang, Q. Lü, and F. M. Li, "Influence of basicity on separated granulating sintering of vanadium titanium magnetite," Journal of Northeastern University, vol. 32, no. 9, pp. 1269-1273, 2011.

[4] W. G. Fu, Y. C. Wen, and H. E. Xie, "Development of intensified technologies of vanadium-bearing titanomagnetite smelting," Journal of Iron and Steel Research, International, vol. 18, no. 4, pp. 7-10, 2011.

[5] Y. Q. Bai, S. S. Cheng, and Y. M. Bai, "Analysis of vanadiumbearing titanomagnetite sintering process by dissection of sintering bed," Journal of Iron and Steel Research International, vol. 18, no. 6, pp. 8-36, 2011.

[6] Y. Q. Bai and S. S. Cheng, "Research on reduction degradation mechanism of low titanium sinter," Sintering and Pelletizing, vol. 37, no. 1, pp. 1-5, 2012.

[7] Y. Q. Bai, S. S. Cheng, H. B. Zhao, and S. F. Huo, "Study of V-Ti sinter reduction degradation by mineralogical analysis," Sintering and Pelletizing, vol. 36, no. 2, pp. 1-6, 2011.

[8] B. Hu, Z. C. Huang, T. Jiang, and Y. B. Zhang, "Experimental study on enrichment oxygen ignition of iron ore sintering," Journal of Iron and Steel Research, vol. 22, no. 12, pp. 17-21, 2010.

[9] X. W. Liu and C. J. Huang, "Experimental study on oxygen enriched sintering of iron ore powder," Powder Metallurgy Industry, vol. 26, no. 5, pp. 38-42, 2016.

[10] H. Ahn, S. Choi, and B. Cho, "Process simulation of iron ore sintering bed with flue gas recirculation Part 2-parametric variation of gas conditions," Ironmaking and Steelmaking, vol. 40, no. 2, pp. 128-137, 2013.
[11] T. Umadevi, P. Karthik, P. C. Mahapatra, M. Prabhu, and M. Ranjan, "Optimisation of $\mathrm{FeO}$ in iron ore sinter at JSW Steel Limited," Ironmaking and Steelmaking, vol. 39, no. 3, pp. 180-183, 2012.

[12] S. L. Wu, Q. F. Wang, M. L. Bian, J. Zhu, and F. Y. Long, "Influence of iron ore characteristics on $\mathrm{FeO}$ formation during sintering," Journal of Iron and Steel Research, International, vol. 18, no. 5, pp. 5-10, 2011.

[13] Q. Lü, X. S. Zhang, X. J. Liu, and Y. N. Qie, "Effect of FeO on properties of low titanium sinters," Iron Steel Vanadium Titanium, vol. 36, no. 1, pp. 68-72, 2015.

[14] N. J. Bristow and C. E. Loo, "Sintering properties of iron ore mixes containing titanium," Isij International, vol. 32, no. 7, pp. 819-828, 2007.

[15] M. Sinha, S. H. Nistala, S. Chandra, T. R. Mankhand, and A. K. Ghose, "Correlating mechanical properties of sinter phases with their chemistry and its effect on sinter quality," Ironmaking and Steelmaking, vol. 44, no. 2, pp. 100-107, 2017. 

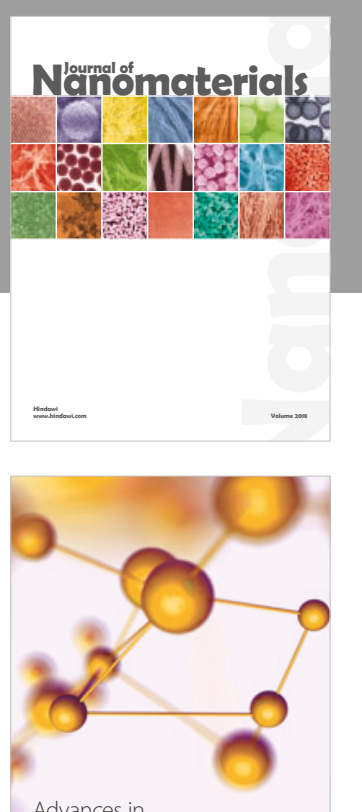

Physical Chemistry
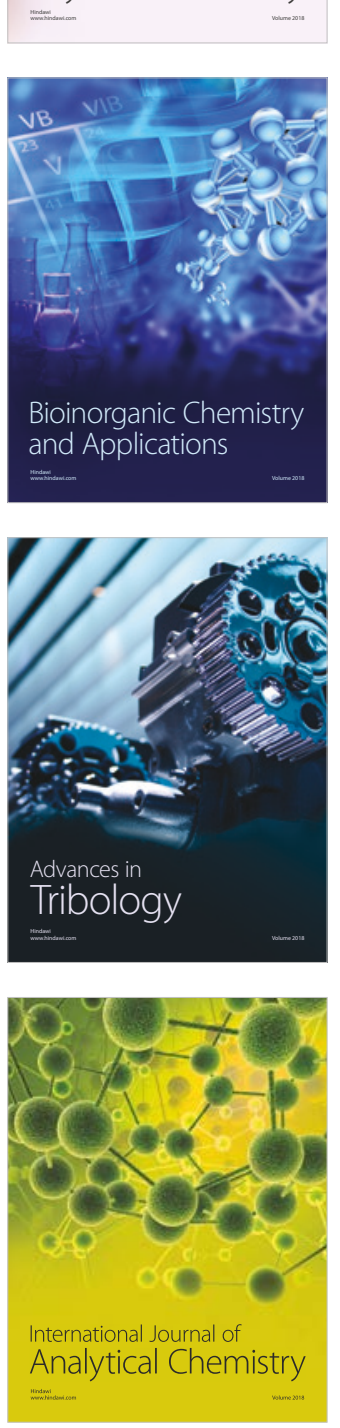

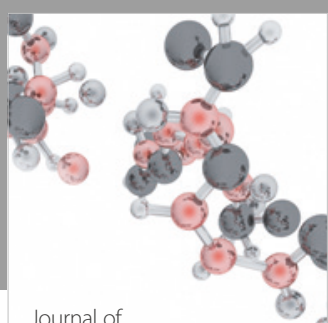

Analytical Methods

in Chemistry

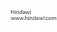

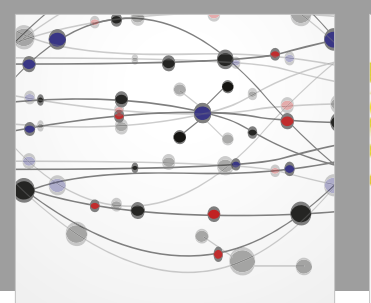

The Scientific World Journal

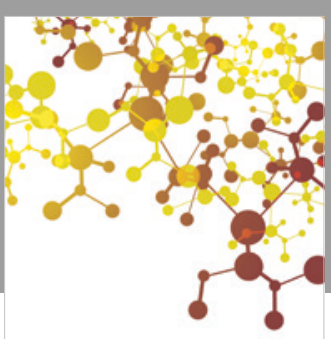

Journal of

Applied Chemistry
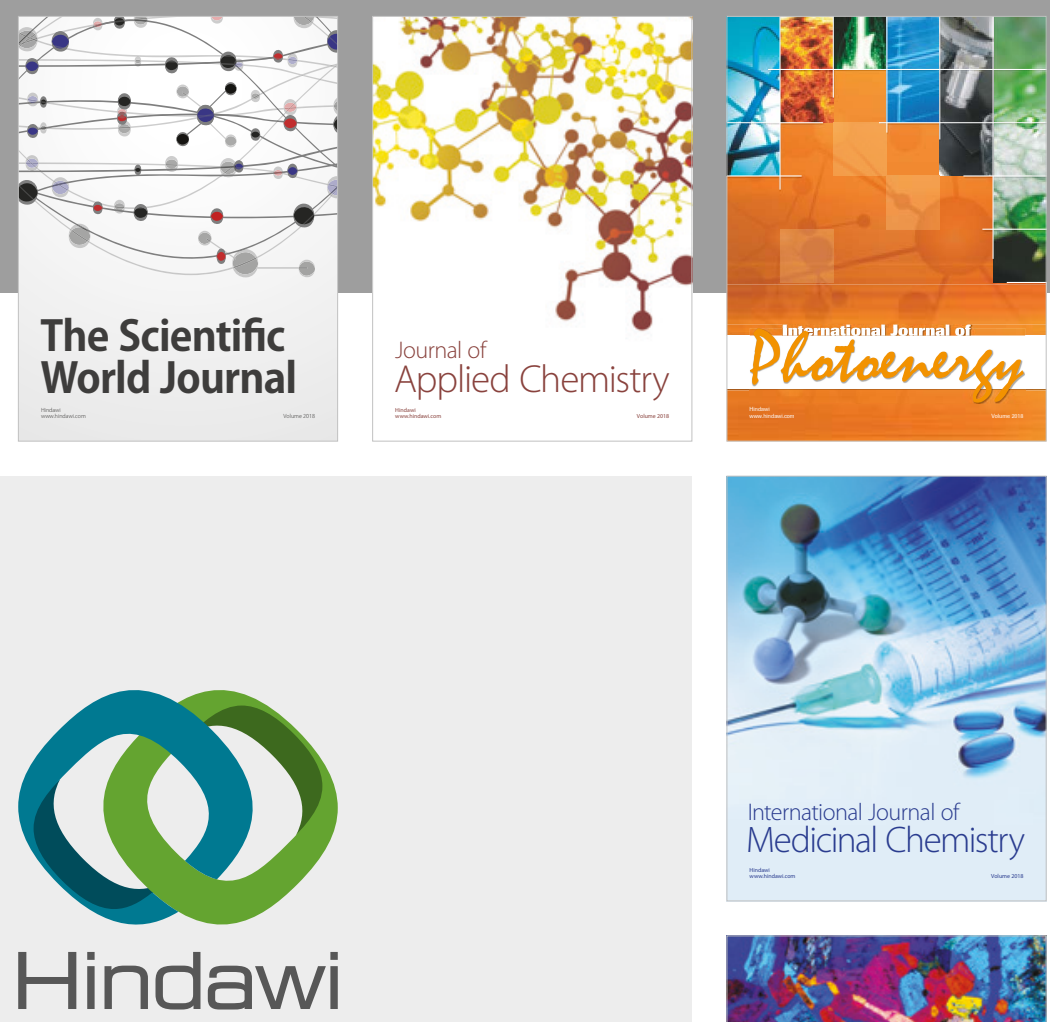

Submit your manuscripts at

www.hindawi.com
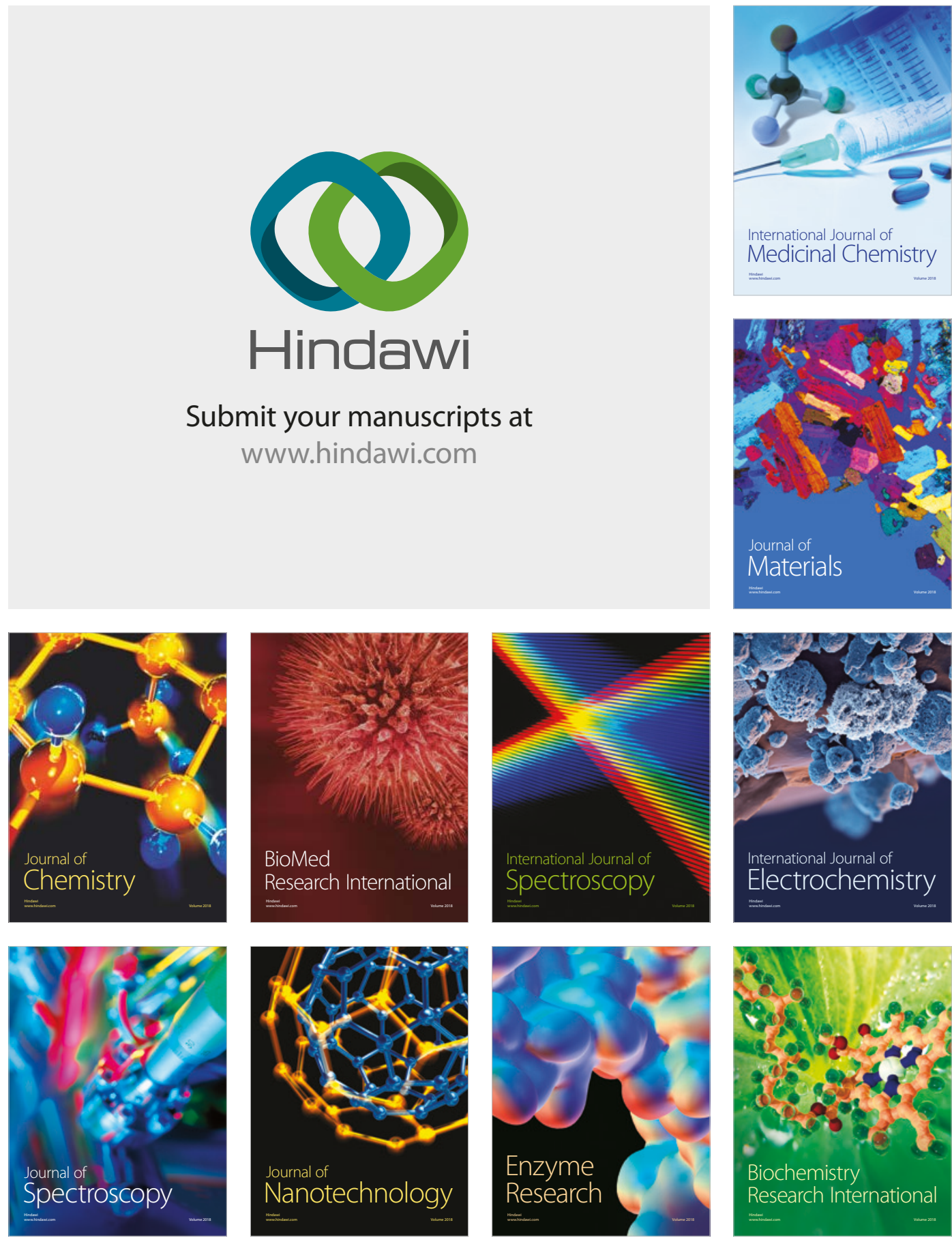
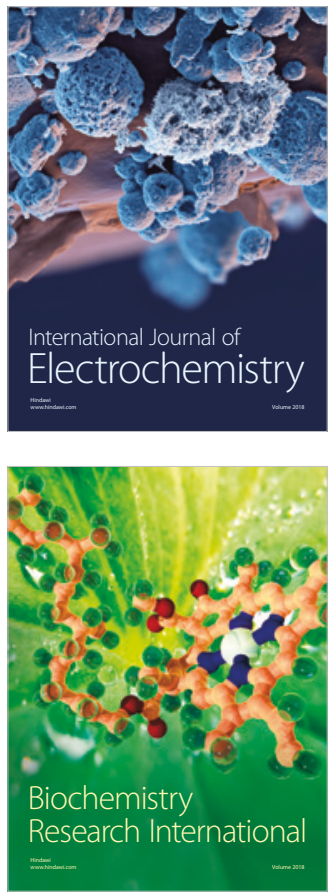